\title{
A PEDAGOGIA ENTRE O PASSADO E A CONTEMPORANEIDADE: APONTAMENTOS PARA UMA RESSIGNIFICAÇÃO EPISTEMOLÓGICA
}

\author{
José LeOnardo Rolim de Lima Severo \\ Universidade Federal do Piauí (UFPI), Picos, Piauí, Brasil \\ Selma Garrido Pimenta \\ Universidade de São Paulo (USP), São Paulo, Brasil
}

\begin{abstract}
Resumo: Este artigo reúne perspectivas conceituais diversas para discutir o caráter que performa as propriedades identitárias da Pedagogia. O texto se organiza em duas sessões que compreendem a análise crítica do contexto de significação epistemológica da Pedagogia, focalizando circunstâncias que deram lugar à emergência de diferentes formas de reconhecimento de sua natureza, e apontamentos que evidenciam o estatuto epistemológico da Ciência da Educação. Infere-se que o lugar da Pedagogia entre o passado e a contemporaneidade será determinado pelo enfrentamento epistemológico quanto a sua problemática identitária e que as circunstâncias da educação na sociedade atual requerem um sistema de saberes e fazeres educativos que exprimem a necessidade de ressignificação dessa Ciência.
\end{abstract}

Palavras-chave: Pedagogia. Ciência da Educação. Epistemologia. Conhecimento pedagógico.

AsPECTOS INTRODUTÓRIOS

Em um contexto histórico marcado pela pluralidade de enfoques que se dirigem a vários aspectos dos processos educacionais, a configuração de 
um discurso epistemológico sobre a Pedagogia alinhado às especificidades do tempo presente e aos desafios inerentes às suas problemáticas sociais, culturais, políticas e econômicas, representa uma atitude de busca por reorganização da Pedagogia enquanto campo de conhecimento, processo de formação e base de intervenção profissional (FRANCO, LIBÂNEO; PIMENTA, 2007).

Como qualquer campo científico, a Pedagogia é confrontada por demandas que atravessam o universo das práticas educativas associadas ao desenrolar da história em seus múltiplos nexos, de modo que faz sentido afirmar a necessidade de que"[...] é preciso que se reivindique à Pedagogia um estatuto contemporâneo que possa absorver as especificidades do momento histórico atual" (FRANCO, 2008, p.131). Esse processo de alinhamento crítico e de diálogo com as circunstâncias históricas atuais constitui um eixo de autorreflexão para que as Instituições da Pedagogia como conhecimento, formação e profissão, se examinem e determinem linhas de desenvolvimento e avanço científico. Assim, a Pedagogia pode adquirir condições de se legitimar como um saber-fazer crítico pertinente e relevante à contemporaneidade, pois

Life continues to change at an increasingly fast pace. The global knowledge base is growing exponentially and the social fabric of our societies is being altered by the massive expansion of communications. Pedagogy must change to keep up with these developments. It must seek to engage those who would otherwise be excluded. It must also support all learners to generate knowledge and to learn what to do when faced with uncertainty (WATKINS; MORTIMORE, 1999, p. 16). ${ }^{2}$

Em face de tal perspectiva, este texto tem como objetivo discutir elementos que problematizam o significado da Pedagogia como Ciência da Educação necessária à construção de reflexões, princípios e proposições educativas na sociedade contemporânea, historicamente marcada pela pluralidade de demandas e novas configurações em torno dos processos de ensinar e aprender. Para tanto, põe em debate a necessidade de ressignificação da Pedagogia com base no reconhecimento de sua natureza como

2 A vida continua a mudar em um ritmo cada vez mais rápido. A base de conhecimento global está crescendo exponencialmente e o tecido social das nossas sociedades está sendo alterado por uma enorme expansão das comunicações. A pedagogia deve mudar para acompanhar esses desenvolvimentos. Ela deve buscar o engajamento daqueles que, de outra forma, seriam excluídos. Ela deve também apoiar todos os aprendizes a gerar conhecimento e aprender o que fazer quando confrontados com a incerteza. (Tradução nossa). 
Ciência da Educação, problematizando diferentes registros conceituais para afirmar que o seu lugar, entre o passado e a contemporaneidade, será definido de acordo com as escolhas epistemológicas que desdobrarão movimentos institucionais distintos.

Os autores introduzidos no texto aportam contribuições que refletem distintas concepções de ciência, da atividade investigativa e do referencial identitário da Pedagogia. Contudo, representam posições que convergem quanto ao reconhecimento da especificidade da Pedagogia com relação a outros campos científicos e a importância da construção de uma agenda reflexiva que provoque o debate sobre as demandas e possibilidades de revisão dos referenciais identitários mobilizados para construir, justificar e aplicar conhecimentos pedagógicos na análise e proposição educativas no contexto contemporâneo. Desse modo, o eixo de articulação que possibilita a sistematização das contribuições dos autores agrega os elementos utilizados pelos mesmos para a formulação de argumentos sobre a especificidade da Pedagogia e das vias epistemológicas que propõem para a justificação de um discurso que reconhece sua identidade teórico-metodológica e suas inserções no universo dos saberes e fazeres em educação.

Panorama e crítica epistemológica da Pedagogia: por uma epistemologia CONSTRUCIONISTA

Watkins e Mortimore (1999) refletem sobre a situação da Pedagogia em países de língua inglesa, informando que o uso do vocábulo "Pedagogia" ainda é permeado por dúvidas e recusas. Informam que, na União Europeia, o termo é mais comumente utilizado em países como França, Alemanha e Rússia do que no Reino Unido e Irlanda, por exemplo. Nesses últimos países, a comunidade acadêmica atribui significados distintos ao termo, variando desde ciência do ensino até cultura docente. Entretanto, ressaltam que "where the writers have used the therm, they have ofted been criticized for using a illdefined and poorly developed idea"3 (WATKINS; MORTIMORE, 1999, p. 1).

3 Onde os autores usaram o termo, eles têm sido muitas vezes criticados por usar uma ideia mal definida e mal desenvolvida. (Tradução nossa). 
Importa dizer que a Pedagogia, atualmente, com maior ou menor intensidade, ocupa lugares de significação semântica em quase todas as partes do mundo, servindo de termo designador de institutos, escolas profissionais, departamentos institucionais, centros de pesquisa, linhas de investigação, entre outros, de tal modo que, conforme sublinha Brezinka (2007), é recorrentemente usado em discursos sobre educação, e, portanto, adquire densidade semântica em se tratando do aspecto quantitativo de expansão do termo e da ideia que o acompanha.

O referido autor problematiza que a Pedagogia vive, hoje, uma posição institucional no ramo dos estudos científicos que se caracteriza pela contradição entre ascensão e crise. Ele enfoca elementos desafiadores que acompanham o avanço institucional que a Pedagogia vivenciou ao longo dos dois últimos séculos. Entre os principais elementos elencados, destacam-se:

[...] subdivisión de muchas ramas en lugar de florecimiento, lejanda de la vida en vez de proximidad a la realidad, jerga terminológica en lugar de conceptos claros, pobreza teorética en vez de adquisición de conocimiento, mucha apariencia y poca sustancia, una conciencia de crisis en lugar de um orgullo justificado por los logros conseguidos. ${ }^{4}$ (BREZINKA, 2007, p. 141).

Brezinka (2007) retoma aspectos nevrálgicos das principais críticas que sugerem a existência de uma crise instalada no seio da Pedagogia, as quais, muitas vezes, deixam de ser objeto de reflexão e autocrítica por parte das próprias Instituições Pedagógicas. O ponto de partida para superação dessa condição de crise parece ser a reconstrução de um discurso epistemológico que esteja relacionado"[...] en gran medida, con las dificultades y los avatares (intelectuales y sociales) de su constituición como saber y en relación a otros saberes"s (LARROSA, 1990, p. 26).

Em concordância com a perspectiva de que o ponto de partida para ressignificar a Pedagogia diante de novos contextos e desafios educativos contemporâneos consiste em uma reflexão de natureza epistemológica,

\footnotetext{
4 Subdivisão de muitos ramos em lugar de florescimento, distanciamento da vida em vez da proximidade com a realidade, jargões terminológicos em lugar de conceitos claros, pobreza teórica em vez de aquisição de conhecimentos, muita aparência e pouca substância, uma consciência em lugar de um orgulho justificado pelos resultados conseguidos (Tradução nossa).

5 em grande medida, com as dificuldades e os avatares (intelectuais e sociais) de sua constituição como saber e em relação a outros saberes. (Tradução nossa).
} 
Pimenta (2000b) destaca que a urgência de tal reflexão responde a uma necessidade histórica e não somente por uma questão lógica ou disciplinar, já que o escanteamento de tal pauta reflexiva resulta na desarticulação entre as novas configurações das práticas sociais de educação e o papel que a pesquisa educacional deve ocupar com o propósito de construir saberes que fertilizem os processos de ensino-aprendizagem com perspectivas de mudança efetiva.

A ressignificação epistemológica da Pedagogia implicaria, pois, afirmá-la como Ciência viável à práxis educativa, a fim de construir, acumular e mobilizar estruturas de análise teórica e empírica com rigor metodológico, de modo que supere as limitações pelas quais "la historia de la Pedagogía reciente sería como una historia de 'dogmas que se combaten y destruyen unos a otros"'6 (BREZINKA, 2007, p. 141).

Ao longo da história, a Pedagogia foi tentada a assumir estatutos científicos cujas bases se encontravam em paradigmas epistemológicos formais pertencentes às Ciências Exatas e Naturais. Igualmente, a aproximação com outras ciências sociais e humanas fez com que fossem transpostas ao campo dos objetos da investigação pedagógica estruturas epistemológicas de campos científicos diversos, como ocorreu no âmbito da proposta de cientifização sistematizada por Herbart, em que o caráter científico da Pedagogia seria advindo da Psicologia, e nas reflexões de Durkheim, nas quais a Pedagogia não se constituiria essencialmente como uma ciência, e sim como uma teoria prática com base no estudo sociológico da educação, conforme pontua Franco (2008).

De acordo com Larossa (1990), para que a Pedagogia atravesse esse umbral de cientificização torna-se necessária a construção de um discurso epistemológico que estabeleça rupturas entre o modo de construção do conhecimento pedagógico e o padrão formal advindo de outros campos científicos, cujo fundamento se estabelece a partir dos princípios da Epistemologia Clássica. Esse novo discurso epistemológico, concebido por Larossa como sendo de natureza construcionista, permitiria à Pedagogia configurar

6 a história da pedagogia recente seria como uma história de 'dogmas que se combatem e destroem uns aos outros.' (Tradução nossa). 
métodos e ferramentas de elaboração e validação de conhecimentos que exprimem o seu caráter histórico, multirreferencial, dinâmico e complexo.

Ou seja, Larossa propõe uma epistemologia interna, válida e relativa ao âmbito específico da Pedagogia, formulada e sujeita a modificações com base no princípio de "sensibilidade contextual", uma vez que a Epistemologia Clássica de caráter formalista e logicista, modelada no âmbito das Ciências Exatas e Naturais, não compreenderia a heterogeneidade de problemáticas e especificidades que envolvem a produção de conhecimento em campos científicos cujos objetos de saber se constituem por múltiplas dimensões teóricas, empíricas, práticas, tecnológicas, axiológicas e teleológicas.

De fato, a epistemologia clássica configura um padrão de racionalidade insuficiente para descrever, explicar e compreender fenômenos contemporâneos inscritos em áreas de conhecimento marcadas pela permeabilidade das subjetividades, sistemas político-ideológicos e estruturas axiológicas. Nesse sentido, pode-se afirmar que

La insuficiente racionalidad testimonia, a su vez, la crisis de las formas de pensamiento, y com ellas la desmitificación de la objetividad de la ciencia, la desacralización de la validez o veracidad de sus proposiciones y el desenmascaramiento de su pretendida neutralidad ideológica ${ }^{7}$ (CARRASCO, 1983, p. 20).

Carrasco (1983) argumenta que a formulação de uma epistemologia interna à Pedagogia desatrelada do padrão formalista e logicista clássico implica em uma transição histórica que configuraria um novo marco conceitual para essa ciência. Ao invés de centrar-se em pressupostos estabelecidos de forma geral e indiferenciada, a Pedagogia deverá organizar-se sob a perspectiva de desenvolver uma teoria para si mesma, cuja validade resultaria da legitimação atribuída por uma comunidade científica institucionalmente integrada.

Os argumentos conjecturados por Larrosa dirigem-se para o entendimento da ciência como uma atividade social, cuja validação encontra-se menos em teorias clássicas absolutas e mais na busca por uma sensibilidade

7 A insuficiente racionalidade testemunha, por sua vez, a crise das formas de pensamento e, com elas, a desmitificação da objetividade da ciência, a dessacralização da validade ou veracidade de suas proposiçõese o desmascaramento de sua pretensa neutralidade ideológica. (Tradução nossa). 
epistemológica contextual que imprima rigor conceitual e orientação práxica para os processos investigativos. Segundo o autor

Considerar la ciencia como actividad supone poner el énfasis en la dinâmica de la investigación o, dicho en términos más precisos, en el proceso en el que se construye conocimiento aceptado. Eso implica considerar su carácter local [...], su carácter social [...], su carácter instrumental [...], su carácter regulado [...]. En definitiva, analizarla como cualquier outra actividad humana en la que se producen y se transforman objectos com determinadas herramientas, para determinados fines y determinados contextos relevantes ${ }^{8}$ (LARROSA, 1990, p. 75).

A partir dessas assertivas, considera-se que uma epistemologia interna sensível aos problemas concernentes à identidade da Pedagogia como ciência possibilita: a) o reconhecimento integral do objeto da Pedagogia como sendo a prática social da educação em suas dimensões teleológica, axiológica e tecnológica; b) reconhecimento da indissociabilidade entre teoria e prática em Pedagogia; c) intensificação do impacto dos resultados de investigação pedagógica no contexto das intervenções educativas em cenários formais, não formais e informais; d) revitalização da teoria pedagógica como um instrumento pertinente ao desenvolvimento social com vistas ao progresso cultural, humano, científico e tecnológico; e) desenvolvimento de métodos e instrumentos de abordagem de novas realidades educativas; $f$ ) formulação de categorias teóricas que descrevam e expliquem a especificidade do domínio pedagógico entre as demais ciências; g) sistematização de princípios que apontem caminhos para reorganização curricular dos cursos de formação de pedagogos na perspectiva de adequá-los à natureza da Pedagogia como Ciência da Educação; $h$ ) reconstrução do estatuto profissional do pedagogo a partir da compreensão do trabalho pedagógico como sendo uma ação profissional inscrita no âmbito da Pedagogia cuja fundamentação requer formação teórica e tecnológica especializada.

8 Considerar a ciência como atividade supõe colocar a ênfase na dinâmica da investigação, ou, dito em termos mais precisos, no processo em que ela constrói o conhecimento aceito. Isso implica considerar seu caráter local, seu caráter instrumental, seu caráter regulado. Definitivamente, analisá-la como qualquer outra atividade humana na qual se produzem e se transformam objetos com determinadas ferramentas, para determinados fins e determinados contextos relevantes. (Tradução nossa). 
A partir dessas considerações é possível elencar alguns elementos que ilustram a perspectiva da Pedagogia como Ciência da Educação em contraposição à perspectiva que a identifica como tecnologia do ensino ou como instrumentalização didática puramente prescritiva e normativa. De certo, a abordagem que segue não corresponde a um apanhado total e exaustivo da literatura dedicada ao tema nem se propõe representar uma perspectiva conclusiva sobre o mesmo. Intenta-se pôr em reflexão elementos que operam uma mudança de compreensão acerca do que se constitui como Pedagogia e, em consequência, dos critérios de racionalidade com os quais os pedagogos podem operar para construir teorias e desenvolver práticas pedagógicas.

\section{A Pedagogia Como CiênCIA da EduCAÇão: uma PeRSPECTIVA RESSIGNIFICADA}

A definição da Pedagogia como Ciência da Educação se aporta no reconhecimento multidimensional do fator científico que configura a abordagem pedagógica, distanciando-a, desse modo, de uma matriz positivista que, como explicita Larrosa (1990), acaba negando o modelo de cientificidade multidimensional por afirmar o modelo de ciência formal inspirado nas Ciências Exatas. Definir a Pedagogia como Ciência a partir do Positivismo incorreria na sua própria negação, haja vista que sua natureza como ciência cujo objeto de conhecimento requer uma atitude investigativa praxiológica, entraria em contradição com a pretensão de neutralidade axiológica e enfoque puramente descritivo.

Dias de Carvalho, por sua vez, afirma que a definição de uma Pedagogia como Ciência fundamentada no que ele descreve como "objetivismo forte" "'...] constrangeria e esvaziaria, em última análise, o necessário desenvolvimento das teorias e das práticas educativas" (1992, p.104). Essa crítica demonstra-se válida quando se considera o que Estrela (1980) denomina de "irredutível pedagógico": o conjunto de elementos que se explicitam apenas no movimento das práticas que configuram as situações de formação humana, os quais não poderiam ser analisados e compreendidos por meio de uma postura investigativa objetivista, pois demanda uma abordagem centrada prioritariamente em aspectos qualitativos. 
Nesse sentido, a proposição da Pedagogia como Ciência da Educação requer uma fundamentação em outra perspectiva acerca do que consiste ser a Ciência e sua funcionalidade diante das necessidades humanas. Tal qual explica Larrosa (1990), essa fundamentação deve ser resultado de um trabalho epistemológico interno à Pedagogia, feito a partir de uma reflexão construcionista sensível às especificidades da área e validada por princípios com adequação contextual.

Tendo a educação como um âmbito da realidade humana, a Pedagogia é uma Ciência que, em sua dimensão filosófica e científica, fundamenta conhecimentos teóricos para a compreensão e explicação dos fatos educativos; em sua dimensão tecnológica descreve o processo educativo a partir de ferramentas e modelos úteis à prática; e que, em sua dimensão praxiológica, estabelece princípios normativos e aplicativos que dinamizem criticamente as práticas educativas reflexivas. $O$ mútuo imbricamento entre essas três dimensões permite afirmar a Pedagogia como"la ciencia que aporta la fundamentación teórica, tecnológica y axiológica dirigida a explicar, interpretar, decidir yordenar la práctica de la educación"9 (RUBIO; ARETIA; CORBELLA, 2008, p.181).

Até mesmo entre os pesquisadores que reconhecem a especificidade científica da Pedagogia, a definição do seu caráter ou matriz identitária é um aspecto que explicita grande diversidade de acepções.

Brezinka $(1990 ; 2007)$ define a Pedagogia como uma ciência composta por quatro classes principais: a Pedagogia Prática, a Pedagogia Empírica, a Pedagogia Filosófica e a Metapedagogia, ou Teoria da Pedagogia. Em cada classe, são produzidos conhecimentos que, articulados entre si, dão conta da totalidade que abrange o objeto educacional. Para além da sistematização interna a si própria, a Pedagogia também se organiza com base na subdivisão disciplinar de outras áreas de conhecimento, em regime de colaboração interdisciplinar, o que a torna uma "ciência integrativa" com o desenvolvimento de teorias em diferentes níveis.

Após considerar um conjunto de problemáticas atinentes ao conceito de ciência no âmbito da Epistemologia e localizar elementos relacionados à

9 "A ciência que aporta a fundamentação teórica, tecnológica, e axiológica dirigida a explicar, interpretar, decidir e ordenar a prática da educação." (Tradução nossa). 
discussão sobre o campo científico da educação, Pérez Serrano chega à conclusão que"[...] se prodía indicar que la Pedagogía es una ciencia del espiritu que proporciona un conocimiento ideográfico y utiliza la comprensión como método para intepretar la acción y las relaciones sociales"10 (2009, p. 67).

Schmied-Kowarzik (1983), por sua vez, defende a Pedagogia como uma ciência dialética para enfatizar a dimensão práxica que constitui a natureza da Ciência da Educação, vista pelo autor como aspecto identitário fundamental. Concebendo a Pedagogia como ciência da e para a prática educativa, ele esclarece que tal caráter não a restringe a uma tecnologia da ação ou uma ciência profissional pragmática como a Medicina, "[...] mera transmissora de conhecimentos para o domínio de aptidões técnicas e artesanais da orientação do ensino" (SCHIMIED - KOWARZIK, 1983, p.12).

Na perspectiva do autor, o termo dialética é usado para designar a interface entre teoria e prática que se constrói por meio da pesquisa das situações educativas e da realidade histórica e social na qual estão inseridas sob um ponto de vista crítico e um ideal emancipatório. A partir desse entendimento, Schmied-Kowarzik reflete que a Pedagogia Dialética, Ciência da Educação, somente pode abordar a realidade empírica de modo crítico quando fundamentada em uma teoria crítica da sociedade. Esse é o princípio da práxis pedagógica possibilitada pela Pedagogia como Ciência. A práxis emerge como processo reflexivo e operativo, guiado não pela inspiração metafísica nem pela imposição da natureza, mas pela ação teórica de autodeterminação humana. Ao afirmar que “[...] exige-se uma teoria que não tem objetivo em si mesma, mas na realização efetiva de uma atividade humana de sentido autodeterminado e que, portanto, é uma ciência da práxis para a práxis" (1983, p. 23), o autor propõe que cabe à Pedagogia motivar a autodeterminação de sentido dos sujeitos educativos através de um marco de investigação no qual o fenômeno educacional é inserido em um contexto mais amplo de crítica social e reconhecimento dos mecanismos que impedem a emancipação dos sujeitos.

10 "se poderia indicar que a Pedagogia é uma ciência do espírito que proporciona um conhecimento ideográfico e utiliza a compreensão como método para interpretar a ação e as relações sociais." (Tradução nossa). 
Na mesma linha teórica em que se situa Schmied-Kowarzik, encontra-se Wilfred Carr. O filósofo britânico defende a ideia de uma Ciência Crítica da Educação fortemente aportada pela reflexão de Habermas. Carr (2002) define sua proposta de ciência crítica em contraponto à proposta de ciência empírica. A Ciência Crítica da Educação teria como objetivo aperfeiçoar a racionalidade dos educadores e sustentar práticas educativas conscientizadoras, empregando um método crítico e autocrítico. Por meio de uma postura metodológica radicalmente crítica, a Ciência da Educação colaboraria com a explicitação das lógicas subjacentes às racionalidades que orientam os processos educativos e permitiria, aos educadores, conhecer e atuar melhor face ao fenômeno educacional como uma realidade situada historicamente e permeada ideologicamente.

Franco (2008) aborda a Pedagogia como Ciência da Educação demonstrando conexões conceituais bastante próximas com o pensamento de Schmied-Kowarzik e Carr. Em uma das principais obras dedicadas à discussão sobre a identidade da Pedagogia no Brasil, que envolve enfoques epistemológicos, metodológicos e formativos, a autora estabelece o percurso histórico de constituição da Pedagogia, distingue as perspectivas que a identificam como arte, tecnologia e ciência, para delinear uma proposta de estruturação da mesma como Ciência Práxica da Educação, fundada no pensamento crítico-dialético, cuja metodologia abarcaria a dimensão formativa e a dimensão emancipadora.

O teórico português Dias de Carvalho (1992), por fim, critica tanto a matriz epistemológica positivista quanto a compreensiva e sugere uma Ciência da Educação de caráter integrativo, por supor que o objetivismo forte, o formalismo e os procedimentos quantitativos concernentes à primeira, bem como o relativismo e o subjetivismo atinentes a segunda limitam a abordagem da Pedagogia a dimensões que necessitam ser compreendidas em relação umas com as outras, de modo complementar. Sugere, ainda, que a investigação-ação é um método apropriado à Pedagogia por possibilitar um movimento integrado entre produção de saberes e formas de intervenção profícuas aos objetivos que assinalam as práticas. Desse modo, a Pedagogia se configura como uma Ciência da Educação que supera os antagonismos 
epistemológicos existentes nas relações entre quantidade e qualidade, teoria e prática, descrição e compreensão.

Concorrentes a tais definições que explicitam posições epistemológicas mais específicas com relação ao entendimento da Pedagogia como ciência, encontram-se outras que tencionam teoria e prática, descrição e compreensão, autonomia funcional e interdisciplinaridade como pontos fulcrais da identidade científica da Pedagogia.

Pimenta (2000a; 2012) e Houssaye (2004) enfatizam que a unidade teoria e prática é um aspecto essencial que configura a identidade da Pedagogia. Fundamentando-se em Schimied-Kowarzik, Pimenta (2012) discute que, sendo o processo educativo uma realidade em constante transformação que demanda reflexão e intencionalidade por parte de quem a realiza, a Pedagogia atua como elemento motivador da práxis, conduzindo-a e modelando-a por meio do aprofundamento teórico e da intervenção prática reflexiva.

A articulação de referências teóricas e práticas através de uma análise educacional que se contextualiza a partir das condições que formam as situações educativas, embasada no rigor científico e na atitude compreensiva e sensível às demandas desse contexto complexo, permite a Pedagogia "[...] produzir um saber específico capaz de orientar a ação sobre o homem e o seu destino. Para isso a condição é articular, com todo rigor epistemológico necessário, as diferentes formas de saber aplicadas" (SOËTARD, 2004, p.62).

Desse modo, a Pedagogia tende a um sentido de totalidade científica que abrange, no aspecto epistemológico, um caráter uno e múltiplo, teórico e prático, definido por seu relacionamento transdisciplinar com os conhecimentos providos por ciências auxiliares, embora mantenha-se como a única ciência capaz de articulá-los tendo em vista a sua vinculação com a práxis educativa.

A educação é um objeto operativo que requer conhecimentos que se situem no plano do saber e, dada sua dimensão prática, do saber-fazer composto por uma interface entre ciência e tecnologia. Essa dimensão tecnológica da Pedagogia é desdobrada do seu próprio objeto. Contudo, tal qual afirma Franco (2008), a Pedagogia não deve ser confundida com tecnologia da educação, pois se assim fosse ela não teria condição de produzir saberes, 
haja vista que estaria restrita ao nível de reprodução e aplicação de práticas modeladas em contextos exógenos.

Torna-se especialmente necessário ressaltar que o termo educação não corresponde à escolarização nem à instrução. $O$ termo designa um processo global de formação humana por meio da inserção dos sujeitos na cultura e sob mediações exercidas por agentes e dispositivos em contextos variados. A Pedagogia tem como objeto a educação enquanto formação humana e não somente a formação escolar ou instrução formal.

O panorama de elementos utilizados para caracterizar a Ciência da Educação, os efeitos desdobrados na construção do seu objeto e método, bem como a finalidade da teoria pedagógica são temas que se inserem em um debate historicamente inconcluso e permeado por dissensos que tencionam posições sobre a autonomia e legitimidade da Pedagogia como tal. A busca pela afirmação desse caráter na Pedagogia implica atravessar as correntes que, historicamente, atuam como as principais formas de negação da sua identidade epistemológica como Ciência da Educação, como exposto ao longo desse texto.

\section{CONSIDERAÇÕES FINAIS}

Um dos caminhos para ressignificação epistemológica inspirada pelas emergências históricas que dão lugar à contemporaneidade consiste em reposicionar a Pedagogia como Ciência da e para a Educação em seus múltiplos nexos e dimensões, fundada na razão práxica e orientada para uma ação transformadora (SCHIMIED-KOWAZIK, 1983).

A travessia epistemológica e institucional da Pedagogia pelo caminho dos desafios decorrentes de tradições que, ora negaram a sua identidade epistemológica como Ciência da Educação, ora fundamentaram um projeto de Pedagogia em aportes que descaracterizaram a sua natureza como ciência dialética e práxica, demanda um processo autocrítico e auto-afirmativo das Instituições Pedagógicas nos campos científico, formativo e profissional.

Com as mudanças ocorridas, relativas aos ideais da educação associados às novas necessidades formativas e ao progressivo acúmulo de referenciais sobre como deve se configurar os processos educacionais, o esforço 
de problematizar a Pedagogia consiste em uma tentativa de pôr em pauta, no âmbito dos estudos, da formação e das práticas pedagógicas, questões que deslocam perspectivas tradicionais e que inauguram novos modos de análise e proposição educativa, os quais não são suficientemente abordados sob os aportes das tradições epistemológicas e institucionais, que até agora viram a Pedagogia como tecnologia da instrução, como arte do ensino ou como ciência aplicada.

Ademais, as respostas dadas no âmbito da Pedagogia derivam de possibilidades epistemológicas de reconfiguração do seu estatuto e dos desdobramentos que são gerados no plano da teoria, da formação e das práticas que lhe estão associadas. Assim, a abrangência da abordagem pedagógica desdobrada nesses planos se atrela a reorganização dos temas de interesse da Pedagogia e permitem a criação de novos setores de estudos especializados.

\section{THE PEDAGOGY BETWEEN THE PAST AND THE CONTEMPORANEITY: NOTES TO AN EPISTEMOLOGICAL RESIGNIFICATION}

ABSTRACT:This paper presents several conceptual perspectives to discuss the character which performs the identity properties of Pedagogy. The text is organized in two sessions: the first one comprises a critical analysis of the context of epistemological significance of Pedagogy, focusing in circumstances that led to the emergence of different forms of recognition of its nature. The second one presents elements that highlight the epistemological status of Educational Science. It is inferred that the place of Pedagogy between past and contemporary times will be determined by epistemological confrontation in relation to its identity issue and the circumstances of education in society today require an educational system of knowledge and practices which express the need to reframe this Science.

KEYworDs: Pedagogy. Educational Science. Epistemology. Pedagogical knowledge.

\section{LA PEDAGOGÍA ENTRE EL PASADO Y LA CONTEMPORANEIDAD: APUNTAMIENTOS PARA UNA RESIGNIFICACIÓN EPISTEMOLÓGICA}

RESUMEN: Este artículo presenta diversas perspectivas conceptuales para discutir el carácter que performa las propriedades identitárias de la Pedagogía. El texto está organizado en dos sesiones que incluyen el análisis crítico del contexto de resignificación epistemológica de la Pedagogía, destacando circunstancias que dieron lugar a 
la aparición de diferentes formas de reconocimiento de su naturaleza, y apuntamientos que demuestran el estatuto epistemológico de la Ciencia de la Educación. Se infiere que el lugar de la Pedagogía entre el pasado y la contemporaneidad será determinado por la confrontación epistemológica acerca de su problemática identitária y que las circunstancias de la educación en la sociedad actual exigen un sistema de conocimientos y prácticas educativas que expresan la necesidad de resignificación de esta Ciencia.

Palabras clave: Pedagogía. Ciencias de la Educación. Epistemología. Conocimiento pedagógico.

\section{REFERÊNCIAS}

BREZINKA, W. Conceptos básicos de la ciencia de la educación. Barcelona: Editorial Herder, 1990.

Educación y pedagogía en el cambio cultural. Madrid: PPU, 2007.

CARR, W. Una teoría para la educación: hacia una investigación educativa crítica. 3. ed. Madrid: Ediciones Morata, 2002.

CARRASCO, J. G. La ciencia de la educación: pedagogos, ¿para qué? Madrid: Santillana S.A. Ediciones, 1983.

DIAS DE CARVALHO, A. Epistemologia das ciências da educação. Porto: Edições Afrontamento, 1996.

ESTRELA, A. Pedagogia ou ciência da educação? Revista Portuguesa de Pedagogia, Coimbra, ano 16, p. 367-372, 1980.

FRANCO, M. A. Pedagogia como ciência da educação. 2. ed. São Paulo: Cortez, 2008. ; LIBÂNEO, J. C.; PIMENTA, S. G. Elementos para a formulação de diretrizes curriculares para cursos de pedagogia. Cad. Pesqui., v. 37, n. 130, p.63-97, abr. 2007.

HOUSSAYE, J. Para uma definição da pedagogia. In: ; SOËTARD, M.; HAMELINE, D.; FABRE, M. Manifesto a favor dos pedagogos. Porto Alegre: Artmed, 2004. p. 9-46.

LARROSA, Jorge. El trabajo epistemológico en pedagogía. Barcelona: PPU, 1990.

PÉREZ SERRANO, G. Pedagogía Social - Educación Social: construcción científica e intervención práctica. 3. ed. Madrid: Narcea, S.A. de Ediciones, 2009.

PIMENTA, S. G. Para uma re-significação da didática - ciências da educação, pedagogia e didática (uma revisão conceitual e uma síntese provisória). In: (Org.). Didática e formação de professores: percursos e perspectivas no Brasil e em Portugal. 3. ed. São Paulo: Cortez, 2000. p. 19-76. 
. O estágio na formação de professores: unidade teoria e prática? 11. ed. São Paulo: Cortez, 2012.

RUBIO, R. M.; ARETIO, L. G.; CORBELLA, M. R. Teoria de la educación - educación social. Madrid: Universidad Nacional de Educación a Distancia, 2008.

SCHMIED-KOWARZIK, W. Pedagogia dialética: de Aristóteles a Paulo Freire. São Paulo: Brasiliense, 1988.

SOËTARD, M. Ciência(s) da educação ou sentido da educação? A saída pedagógica. In: HOUSSAYE, J.; SOËTARD, M.; HAMELINE, D.; FABRE, M. Manifesto a favor dos pedagogos. Porto Alegre: Artmed, 2004. p. 47-70.

WATKINS, C.; MORTIMORE, P. Pedagoy: what do we know? In: MORTIMORE, P. (Org.). Understanding pedagogy and its impact on learning. London: Paul Chapman Publishing, 1999. p. 12-24.

JOSÉ LEONARDO ROLIM DE LIMA SEVERO: Doutor em Educação pela Universidade Federal da Paraíba (UFPB). Professor Assistente da Universidade Federal do Piauí (UFPI). Tem experiência na área de Educação, com ênfase no estudo da Epistemologia da Pedagogia e Conhecimento Pedagógico, Educação Não Escolar, Formação de Pedagogos e Gestão Educacional.

E-mail: leonardorolimsevero@smail.com

SELMA GARRIDO PIMENTA: Doutora em Educação pela Pontifícia Universidade Católica de São Paulo (PUC-SP). Atualmente é Professora Titular Sênior na Universidade de São Paulo (USP), e Professora Assistente da Universidade Católica de Santos (Unisantos). Tem experiência na área de Educação, atuando principalmente nos seguintes temas: formação de professores, didática, pedagogia e pesquisa educacional. Suas pesquisas mais recentes são no campo da Pedagogia Universitária e Docência no Ensino Superior.

E-mail: sspiment@usp.br 